\title{
RANCANG BANGUN MODEL SISTEM REAL MONITORING LALU LINTAS DENGAN MENGGUNAKAN RASPBERRY Pi
}

*Muhammad Yasir ${ }^{1}$, Evta Indra ${ }^{2}$

${ }^{1,2}$ Program Studi Sistem Informasi Fakultas Teknologi dan Ilmu Komputer, Universitas Prima Indonesia

Sekip, Simpang Seikambing, Medan, Indonesia, 20111

E-mail : *risayyasir18@yahoo.co.id

\begin{abstract}
ABSTRAK- Tingkat kecelakaan berkendara yang masih sering terjadi di Indonesia. Sepanjang tahun 2016 tercatat kasus kecelakan lalu lintas lalu sebanyak 27.249 kasus dengan korban meninggal dunia tercatat 6.831 orang. Pada tahun 2017 tingkat kecelakaan lalu lintas mengalami penurunan, tercatat 24.142 kasus kecelakaan lalu lintas dengan korban menginggal dunia sebesar 5.326. Salah satu program untuk menurunkan tingkat kecelakaan lalu lintas dan menertibkan pengendara adalah dengan penerapan sistem real monitoring menggunakan CCTV yang dilengkapi fitur voice streaming pada setiap persimpangan jalan. Pada penelitian ini sistem real monitoring yang dirancang akan menggunakan raspberry pi sebagai pengganti CCTV. Hal ini bertujuan untuk mengurangi biaya pembuatan sistem dan sistem dapat dimodifikasi kembali sesuai dengan kebutuhan serta dapat membantu petugas dalam memonitoring lalu lintas. Sistem juga dilengkapi dengan Radio Frequency Identification (RFID) sebagai tanda pengenal dari setiap kendaraan. Sistem ini dirancang pada platform web dan android yang dilengkapi dengan fitur voice streaming dan menggunakan bahasa pemrograman JAVA. Sistem yang dirancang juga memiliki fitur khusus untuk E-Tilang dan E-Pajak bagi para pengendara yang tidak taat aturan. Hasil dari penelitian ini berupa model mekanisme real monitoring lalu lintas yang dapat diterapkan pada setiap persimpangan jalan. Dengan adanya sistem ini diharapkan tingkat kecelakaan lalu lintas di Indonesia terus menurun untuk setiap tahunnya.
\end{abstract}

Kata kunci : Real monitoring, model system, raspberry pi, android, web

\section{PENDAHULUAN}

Dalam kehidupan sehari - hari manusia sangat membutuhkan trasnportasi sebagai media untuk berpindah dari suatu tempat ke tempat lainya. Tujuan dari penggunaan transportasi ini adalah untuk memudahkan manusia dalam melakukan aktivitas sehari-hari. Transportasi sendiri dibagi 3 yaitu, transportasi darat, laut, dan udara. Di Negara Republik Indonesia trasportasi darat menjadi suatu bagian penting dalam kehidupan masyarakatnya. Hal - hal yang berkaitan dengan trasportasi sudah di atur oleh pemerintah dalam undang - undang sebagai sarana untuk menciptakan ketertiban dan keamanan dalam menggunakan trasportasi tersebut. Salah satunya adalah undang - undang lalu lintas No 22 tahun 2009[1].

Masalah yang dihadapi sekarang adalah tingkat kecelakaan berkendara yang masih sering terjadi. Di Indonesia sepanjang tahun 2016 tercatat kasus kecelakan lalu lintas lalu sebanyak 27.249 kasus dengan korban meninggal dunia tercatat 6.831 orang. Pada tahun 2017 tingkat kecelakaan lalu lintas mengalami penurunan, tercatat 24.142 kasus kecelakaan lalu lintas dengan korban menginggal dunia sebesar 5.326[2]. Walapun kecelakan tersebut tidak dapat dihidari tetapi masih bisa dicegah. Terdapat beberapa faktor yang meyebabkan kecelakaan itu bisa terjadi. Faktor manusia, faktor lingkungan dan faktor peralatan. Dari ketiga faktor tersebut faktor manusialah yang cenderung menyebabkan terjadinya kecelakaan berlalu lintas. Kesadaran dan pemahaman masyarakat akan peraturan dan tata tertib masih sering dihiraukan begitu saja. Salah satu bentuk pelanggaran yang masih sering dilakukan adalah pada saat rambu lalu lintas berhenti masih terdapat beberapa pengendara yang tidak berhenti di tempat yang telah disediakan terutama bagi pengendara sepeda motor. Ruang Henti Khusus (RHK) yang telah disediakan untuk tempat berhenti para pengguna sepeda motor masih sering dihiraukan oleh beberapa pengendara. Hal ini tentu dapat menyebabkan terjadinya kecelakaan.

Seiring berkembangnya teknologi berbagai macam alat sudah dikembangkan untuk mengurangi tingkat kecelakaan lalu lintas. Salah satunya adalah peletakan kamera CCTV dengan fitur voice streaming pada setiap persimpangan. Hal ini di maksudkan untuk menegur dan memperingati pengendara yang tidak berhenti pada tempat yang telah disediakan. Sistem real monitoring ini terbukti efektif dikarenakan adanya tindakan langsung berupa teguran dari para petugas yang melihat dari monitor. Sehingga pengedara - pengendara yang ditegur akan kembali ke ruang berhenti yang telah disediakan dan tidak melewati batas lagi. Tentunya untuk menerapkan sistem ini di setiap pesimpangan bukannya hal yang mudah. Dikarenakan harga alat yang cukup mahal untuk diimplementasikan dan pemantuan masih dilakukan di dalam ruang khusus monitoring.

Beberapa penelitian telah dilakukan untuk membangun sistem real monitoring di berbagai dunia. Banyak penelitian diantaranya menggunakan sensor berupa RFID untuk identifikasi kendaraan (N Ying, 2013, Eun Kyu Lee, 2009). N Ying dkk melakukan penelitian menggunakan metode 
LANDMARC untuk mengetahui lokasi kendaraan yang akurat menggunakan sensor RFID dan GPS (N Ying, 2013)[3]. J.Wang dkk juga meneliti aplikasi RFID adalah untuk mendeteksi posisi kendaraan (J.Wang, 2014). Evizal dkk meneliti tentang pelacakan plat kendaraan dan sistem manajemen kendaraan (Evizal, 2013)[4]. Beberapa penelitian ini menyatakan bahwa sensor RFID sebagai alterntif sensor yang dapat digunakan untuk aplikasi ITS. Selalin sensor hal yang penting pula adalah dalam ITS ketersedian kanal pada komunikasi V2I ini sangat penting sehingga pemilihan teknologi komunikasinya menjadi sangat penting. Eun Kyu Lee dkk telah meneliti beberapa aplikasi RFID Reader pada frekuensi UHF diusulkan untuk beberapa aplikasi kendaraan mulai dari navigasi yang aman dalam aplikasi transportasi cerdas (Eun Kyu Lee, 2009)[5]. Sebagai studi pendahuluan Nuradi dkk telah melakukan studi pendahuluan dengan melakukan pengukuran level daya pada sistem komunikasi existing di sekitar jalan tol untuk mengetahui karakteristik lingkungan, agar dapat digunakan untuk mendukung implementasi ITS di Surabaya (Nuradi, 2014).

Penelitian ini ditujukan untuk merancang suatu model sistem real monitoring lalu lintas yang dapat digunakan untuk memonitoring aktivitas lalu lintas disetiap persimpangan jalan dengan platform android maupun web secara real-time, low-cost secara real monitoring. Serta merancang suatau model sistem real monitoring lalu lintas dengan fungsi-fungsi yang lebih komplit (voice streaming, perekaman data pelanggaran, E-tilang, E-Pajak). Dengan adanya penelitian ini diharapkan hasil dari model yang akan di bangun dapat digunakan untuk perancangan sistem secara konkrit dan pengembangan lebih lanjut.

\section{ISI PENELITIAN}

\subsection{Real User Monitoring}

Real User Monitoring (RUM) adalah teknologi pemantauan pasif yang mencatat semua interaksi pengguna dengan situs web atau klien yang berinteraksi dengan server atau aplikasi berbasis cloud. Memantau interaksi pengguna yang sebenarnya dengan situs web atau aplikasi penting bagi operator untuk menentukan apakah pengguna dilayani dengan cepat dan tanpa kesalahan dan jika tidak bagian mana dari proses bisnis yang gagal. Software As A Service (SaaS) dan Application Service Providers (ASP) menggunakan RUM untuk memantau dan mengelola kualitas layanan yang dikirimkan ke klien mereka. Data pemantauan pengguna nyata digunakan untuk menentukan kualitas tingkat layanan yang sebenarnya dikirim ke pengguna akhir dan untuk mendeteksi kesalahan atau perlambatan di situs web. Data juga dapat digunakan untuk menentukan apakah perubahan yang diundangkan ke situs memiliki efek yang diinginkan atau menyebabkan kesalahan[6].

\subsection{Voice Over Internet Protocol}

Voice Over Internet Protokol (VoIP) merupakan salah satu teknologi yang berkembang saat ini, teknologi ini dapat menjadi alternatif untuk berkomunikasi suara secara langsung dan menggukan protocol TCP/IP. Keunggulan teknologi VoIP yang menonjol adalah dapat dikembangkan dan dikombinasikan dengan GSM gateway untuk terhubung ke jaringan telepon selular. VoIP dapat diimplementasikan didalam suatu organisasi, institusi, dan perusahaan secara mandiri[7].

\subsection{Virtual Private Network}

Virtual Private Network atau biasa disingkat dan dikenal umum sebagai VPN atau VPN tunnel adalah sebuah mekanisme menyambungkan sebuah titik (atau biasa dengan node) pada sebuah jaringan komputer dengan titik melalui sebuah medium secara pribadi, dalam hal ini titik dapat berupa jaringan komputer lokal (atau biasa disebut LAN) atau sebuah komputer. VPN adalah cara aman untuk mengakses local area network yang berada pada jangkauan network yang lain, dengan menggunakan internet atau jaringan umum lainnya untuk melakukan transmisi paket data secara pribadi, paket data ter-enkripsi sehingga pada traffic (lalu lintas) antar remote-site tidak dapat disadap dengan mudah[7].

\subsection{Raspberry Pi 3B}

Raspberry pi adalah sebuah mini komputer atau single boards computer yang berukuran kecil yang dikembangkan oleh yayasan nirlaba raspberry pi foundation, walaupun berukuran kecil raspberry pi cukup handal untuk melakukan tugas-tugas yang dapat dilakukan oleh komputer pada umumnya, bahkan raspberry pi digunakan sebagai web server dan media server. Selain itu Raspberry Phi mampu melakukan segala sesuatu layaknya komputer desktop, dari browsing internet dan menjalankan video high-definition, untuk membuat spreadsheet, pengolah kata, dan bermain game. Raspberry pi memiliki spesifikasi sebagai berikut, prosesor 900 $\mathrm{MHz}$ quad-core ARM Cortex-A7 CPU, RAM sebesar $1 \mathrm{~GB}, 40$ pin general I/O, 4 port USB, port HDMI, port Ethernet, Camera Interface, Display Interface, slot SD card, Audio output [7].

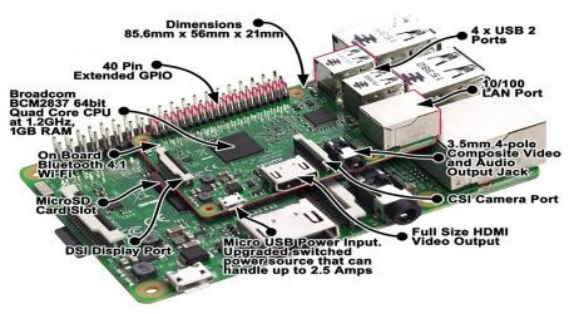

Gambar 1. Raspberry Pi 


\subsection{Android}

Android adalah sistem operasi berbasis Linux yang dirancang untuk perangkat bergerak layar sentuh seperti telepon pintar dan komputer tablet. Android adalah sistem operasi dengan sumber terbuka, dan Google merilis kodenya di bawah Lisensi Apache. Kode dengan sumber terbuka dan lisensi perizinan pada Android memungkinkan perangkat lunak untuk dimodifikasi secara bebas dan didistribusikan oleh para pembuat perangkat, operator nirkabel, dan pengembang aplikasi. Selain itu, Android memiliki sejumlah besar komunitas pengembang aplikasi yang memperluas fungsionalitas perangkat, umumnya ditulis dalam versi kustomisasi bahasa pemrograman Java[8].

\subsection{Java}

Java adalah bahasa pemrograman yang dapat dijalankan di berbagai komputer termasuk telepon genggam. Bahasa ini awalnya dibuat oleh James Gosling saat masih bergabung di Sun Microsystems saat ini merupakan bagian dari Oracle dan dirilis tahun 1995. Bahasa ini banyak mengadopsi sintaksis yang terdapat pada $\mathrm{C}$ dan $\mathrm{C}++$ namun dengan sintaksis model objek yang lebih sederhana serta dukungan rutin-rutin aras bawah yang minimal. Aplikasi-aplikasi berbasis java umumnya dikompilasi ke dalam p-code (bytecode) dan dapat dijalankan pada berbagai Mesin Virtual Java (JVM).

Java merupakan bahasa pemrograman yang bersifat umum/non-spesifik (general purpose), dan secara khusus didesain untuk memanfaatkan dependensi implementasi seminimal mungkin. Karena fungsionalitasnya yang memungkinkan aplikasi java mampu berjalan di beberapa platform sistem operasi yang berbeda, java dikenal pula dengan slogannya, "Tulis sekali, jalankan di mana pun". Saat ini java merupakan bahasa pemrograman yang paling populer digunakan, dan secara luas dimanfaatkan dalam pengembangan berbagai jenis perangkat lunak aplikasi ataupun aplikasi[9].

\subsection{PHP}

PHP adalah bahasa pemrograman script serverside yang didesain untuk pengembangan web. Selain itu, PHP juga bisa digunakan sebagai bahasa pemrograman umum. PHP di kembangkan pada tahun 1995 oleh Rasmus Lerdorf, dan sekarang dikelola oleh The PHP Group. PHP disebut bahasa pemrograman server side karena PHP diproses pada komputer server. Hal ini berbeda dibandingkan dengan bahasa pemrograman client-side seperti JavaScript yang diproses pada web browser (client). Pada awalnya PHP merupakan singkatan dari Personal Home Page. Sesuai dengan namanya, PHP digunakan untuk membuat website pribadi. Dalam beberapa tahun perkembangannya, PHP menjelma menjadi bahasa pemrograman web yang powerful dan tidak hanya digunakan untuk membuat halaman web sederhana, tetapi juga website populer yang digunakan oleh jutaan orang seperti wikipedia, wordpress, joomla, dll. Saat ini PHP adalah singkatan dari PHP: Hypertext Preprocessor, sebuah kepanjangan rekursif, yakni permainan kata dimana kepanjangannya terdiri dari singkatan itu sendiri: PHP: Hypertext Preprocessor. PHP dapat digunakan dengan gratis (free) dan bersifat Open Source. PHP dirilis dalam lisensi PHP License, sedikit berbeda dengan lisensi GNU General Public License (GPL) yang biasa digunakan untuk proyek Open Source[10].

\subsection{Web Server}

Server atau Web server adalah sebuah software yang memberikan layanan berbasis data dan berfungsi menerima permintaan dari HTTP atau HTTPS pada klien yang dikenal dan biasanya kita kenal dengan nama web browser (Mozilla Firefox, Google Chrome) dan untuk mengirimkan kembali yang hasilnya dalam bentuk beberapa halaman web dan pada umumnya akan berbentuk dokumen HTML.

Berbagai aplikasi yang terletak di rumah dapat dikendalikan atau dimonitor dari jarak jauh dengan menanamkan perangkat dengan web server. Informasi statis dan dinamis disimpan dalam sistem tertanam dan memenuhi tuntutan pada browser web. Jenis web server semacam ini disebut web server tertanam.

Ada banyak web server alternatif yang mungkin diinstal pada Raspberry Pi. Server web kuno, seperti Apache, melayani file dari papan Raspberry pi ke pembeli. Raspberry pi juga dapat melayani suara, video, program yang dapat dikerjakan, dan jauh lebih banyak. Namun, ada jenis alat baru yang menjangkau bahasa pemrograman seperti Python, Ruby, dan JavaScript untuk membuat server neto yang secara dinamis menghasilkan bahasa mark-up hypertext begitu mereka menerima permintaan protokol komunikasi dari browser online[11].

\subsection{Radio Frequency Identifier}

Radio Frequency Identifier (RFID) merupakan suatu teknologi yang digunakan untuk mengidentifikasi suatu objek tertentu dengan menggunakan gelombang radio tanpa kabel (wireless). Terdapat tiga komponen utama pada susunan sistem RFID. Ketiga komponen tersebut adalah.

1. RFID Tag

2. RFID Reader (interrogator)

3. Controller (host)

Adapaun proses untuk megidentifikasi dengan menempatkan RFID Tag yang berisi identitas pada suatu objek kemudian identitas ini dibaca secara oleh RFID Reader. 
Data identitas yang dibaca reader ini selanjutnya akan disimpan kedalam Controller. [12]

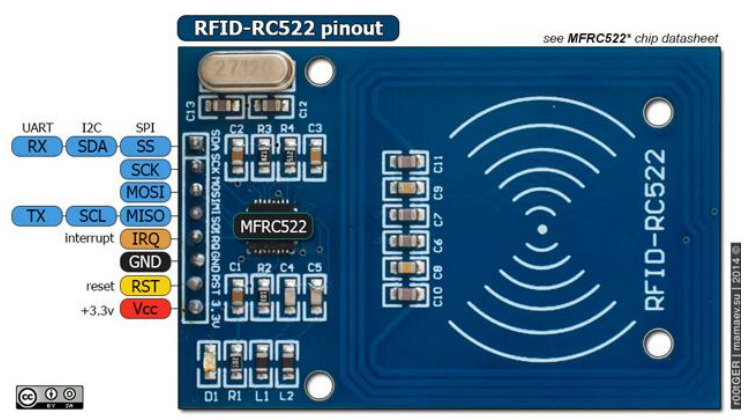

Gambar 2. RFID

\subsection{Radio Frequency Identifier Tag}

Tag merupakan chip penyimpan identitas pada sistem RFID. Berdasarkan sumber energinya terdapat dua tipe RFID Tag. Tipe pertama adalah tag aktif berarti tag yang memiliki sumber energi sendiri, yaitu berupa baterai. Karena memiliki suplai energi tersendiri maka tag aktif ini memiliki jangkauan pembacaan yang lebih jauh daripada tag pasif serta memiliki kemampuan menyimpan data yang lebih besar.

Sedangkan kekurangan dari tag ini adalah ukurannya tidak bisa dibuat sekecil mungkin karena adanya baterai, selain itu juga memiliki jangka waktu pemakain baterai. Sedangkan tag pasif tidak memiliki sumber energi sendiri. Jadi, energinya dapat diperoleh dari pancaran gelombang radio dari reader. Tag ini dapat dibuat sekecil mungkin, tetapi kemampuan penyimpanan datanya sangatlah kecil[13].

\subsection{Radio Frequency Identifier Reader}

RFID Reader atau interrogator memiliki fungsi untuk mengambil data dari RFID tag dengan komunikasi secara wireless dimana akan memanfaatkan gelombang radio. Sedangkan untuk jenisnya dapat disesuaikan dengan tag yang dipakai, karena tag RFID hanya dapat dibaca oleh reader tertentu. RFID Reader mampu membaca data dari beberapa tag secara hampir bersamaan karena memanfaatkan gelombang radio dengan kecepatan baca sampai $6 \mathrm{~ms}$ per 64 bits. Untuk keperluan deteksi jarak jauh telah ada reader dengan range baca sampai $20 \mathrm{~m}[13]$.

\subsection{Controller (host)}

Controler (host) yang digunakan dapat berupa Personal Computer (PC). Controler memiliki fungsi untuk mengatur komunikasi data antara tag dan reader serta sebagai tempat menyimpan informasi (database) yang diperoleh dari tag. Selain itu controller juga dipakai untuk menulis data pada tag jenis RFID read/write. Adapaun proses komunikasi antara reader dan controller akan dilakukan dengan komunikasi secara serial.

\section{HASIL DAN PEMBAHASAN}

Pada penelitian yang akan dilakukan untuk membangun model sistem real monitoring lalu lintas dengan menggunakan raspberry pi akan berfokus pada desain dan rancang bangun model arsitektur sistem. Sebelum melakukan penelitian berbagai studi literatur yang berkaitan dengan topik di pelajari terlebih dahulu demi mendapatkan hasil yang lebih baik. Adapaun langkah - langkah dalam melakukan penelitian ini adalah sebagai berikut:

1. Studi Literatur

2. Analisis dan Perancangan

a. Desain model perancangan alat dengan raspberry pi

b. Desain program dengan menggunakan web dan android

c. Model instalasi jaringan

d. Model komunikasi data

e. Desain model penerapan fitur-fitur pada sistem E-tilang dan E-pajak

f. Desain arsitektur data serta kebutuhan sistem

3. Implementasi algoritma untuk live video dan voice streaming

a. Algoritma live video stream

b. Algoritma voice streaming

c. Penerapan indentifikasi dengan RFID

d. Integragi sistem dengan E-Tilang dan EPajak

4. Uji Coba dan Evaluasi

Adapaun secara umum tahapan penelitian dapat dilihat pada Gambar 3.

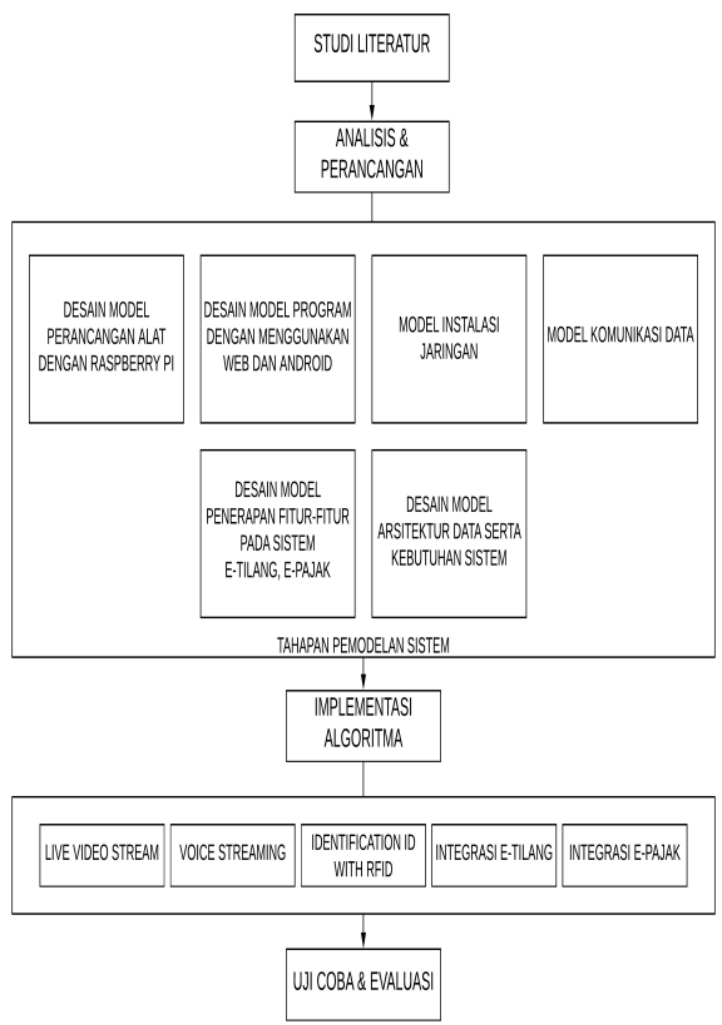

Gambar 3. Tahapan Penelitan 
Adapun model pengembangan perangkat lunak yang digunakan pada penelitian ini adalah waterfall development model. Hal ini bertujuan untuk mendapatkan hasil yang baik dikarenakan model pengembangan ini berfokus pada penyelesaian suatu tahap secara sempurna sebelum melakukan tahap selanjutnya. Adapun skema dari model pengembangan waterfall development model pada penelitian ini seperti yang di tunjukkan pada Gambar 4.

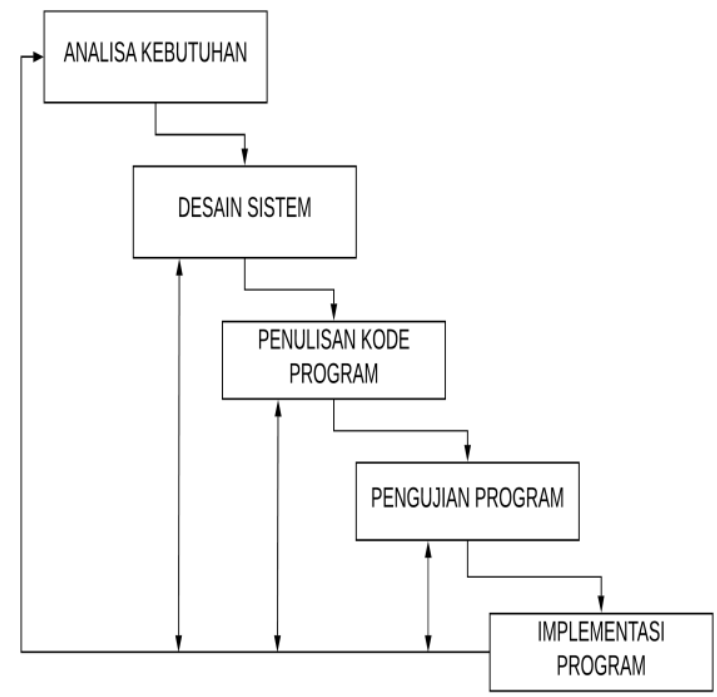

Gambar 4. Waterfall Development Model Sistem

Sedangkan rancangan kebutuhan sistem baik dari segi kebutuhan alat / tools hardware maupun software akan sangat mempengaruhi pengembangan penelitian selanjutnya. Adapun alat-alat yang dibutuhkan adalah sebagai berikut :

Kebutuhan Hardware

1. Raspberry Pi 3B

2. Waterproof case for Raspberry $\mathrm{Pi}$

3. HD Camera

4. Laser Rangerfinder Sensor V1

5. RFID

6. Cable

7. Speaker

8. Microphone

9. PC \& Android Phone

Kebutuhan Sofwatre

1. Android Studio

2. Sublime Text Editor

3. RFID Reader

Kebutuhan Programming Languange

1. Java

2. PHP

3. Python

Pembahasan selanjutnya adalah perancangan model arsitektur sistem secara keseluruhan. Sistem real monitoring lalu lintas dengan menngunakan raspberry pi yang dirancang meliputi beberapa proses yang akan terjadi selama sistem akan berjalan. Diperlukan analisis terhadap model arstitektur sistem secara keseluruhan agar proses real monitoring lalu lintas akan berjalan dengan baik dan sistem dapat memberikan pengaruh yang signifikan. Secara umum desain diagram alir dari sistem akan dibagi kedalam beberapa bagian agar memudahkan penerapan terhadap model yang akan dibangun. Pada penelitian ini model yang di bangun akan berfokus pada bagian untuk proses real monitoring pada lalu lintas serta voice streaming. Adapun diagram alir dari sistem real monitoring lalu lintas dengan menggunakan Raspberry Pi seperti yang terlihat pada Gambar 5.

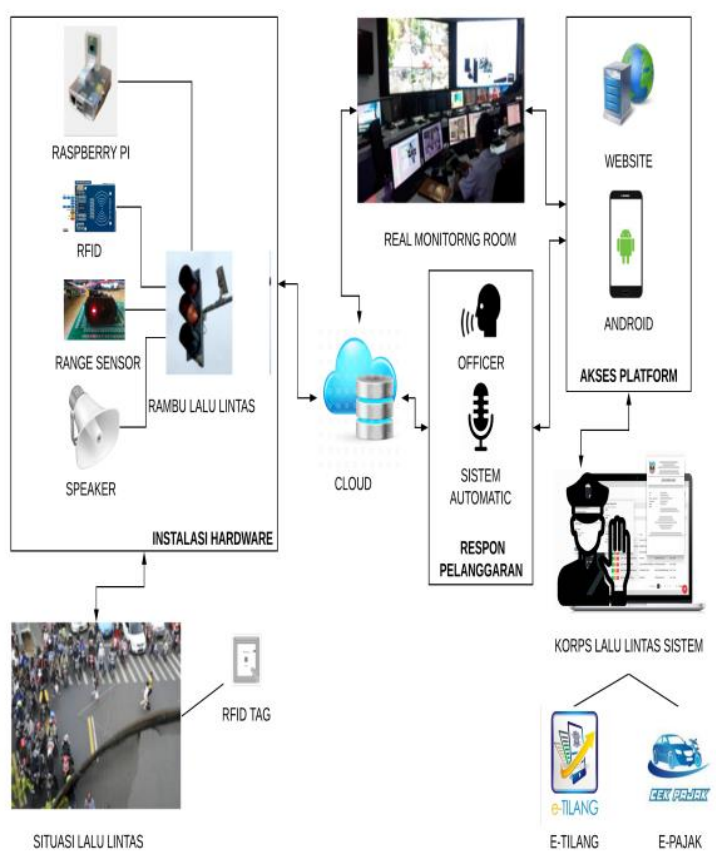

\section{Gambar 5. Diagaram Alir Sistem Real Monitoring Lalu Lintas}

Dari gambar 5 dapat diketahui bahwa sistem yang dirancang akan menggunakan beberapa proses inputan serta output. Pada sistem yang akan di bangun objek yang akan di deteksi oleh sistem adalah adalah kendaraan roda 2 dan roda 4 yang melanggar peraturan (berhenti melewati garis ruang henti kusus). Pada tahapan awal, terdapat proses pendaftaran ID kendaraan dengan menggunakan RFID yang akan mengindentifikasi pengendara. Setiap kendaraan akan menggunakan RFID Tag. Model yang ditawarkan akan melakukan proses entry data pribadi dari pengguna kendaraan. Hal ini bertujuan agar mendukung proses e-tilang dan epajak. Data-data tersebut akan tersimpan kedalam cloud server milik pihak berwenang yang meliki akses untuk melakukan proses tinjak lanjut dari pelanggaran.

Selanjutnya pada bagaian instalasi hardware, alat yang dirancang akan diterapkan / diletakkan di setiap persimpangan lalu lintas. Pada sistem yang akan di rancang, Raspberry $\mathrm{Pi}$ akan digunakan sebagai processor. Raspberry Pi akan di integrasikan 
dengan kamera HD sebagai media untuk mendeteksi situasi lalu lintas. Model yang ditawarkan dari penelitian ini ada penggunaan sensor jarak yang dapat berguna untuk mendeteksi pelanggaran secara otomatis. Sensor tersebut dibutuhkan untuk menjadi trigger agar proses feedback secara otomatis dapat berjalan. Selain dengan cara automatis sistem yang akan dirancang nantinya juga memiliki proses feedback secara manual. Instalasi hardware yang akan dirancang harus terkoneksi dengan internet baik dengan menggunakan kabel ataupun sejenisnya. Hal ini sangat diperlukan karena sistem bersifat online dan secara real time akan melakukan proses monitoring. Sebagai output dari sistem maka dibutuhkan speaker sebagai jalur trasmisi suara dari pihak petugas. Rancangan alat juga akan di koneksikan dengan RFID agar, setiap kendaraan yang telah memiliki RFID tag dapat di deteksi.

Proses inputan dari hardware yang telah di rancang akan terhubung dengan dengan cloud yang langsung dapat di akses oleh petugas dapa ruangan real monitoring. Petugas dapat melakukan proses monitoring dengan menggunakan 2 media akses yaitu website ataupun dengan mobile (android). Selanjutnya sistem yang di rancang akan di integrasikan dengan sistem E-Tilang dan E-Pajak sebagai fitur tambahan dari sistem real monitoring lalu lintas dengan menggunakan Raspberry Pi.

Tahapan selanjutnya adalah proses output, pada sistem ini output yang dihasilkan akan ditujukan kepada petugas di ruang monitoing yang memiliki kewenangan untuk mengakses sistem. Petugas akan melakukan proses real monitoring keadaan lalu lintas secara berkala dan memberikan peringatan kepada pengendara yang melanggar peraturan melalui microphone. Suara tersebut akan ditransmisikan kealat dan output dari speaker yang terhubung dengan alat. Jika petugas tidak ada ditempat, maka sistem real monitoring otomatis akan berkerja. Dengan menggunakan mode aktifasi sensor yang akan menjadi trigger terhadap sistem. Sistem akan mengambil gambar berupa foto kendaran secara otomatis para pelanggar lalu lintas melalui kamera dan disimpan kedalam web server. Dan sistem juga dapat memberikan peringatan secara otomatis kepada pelanggar.

Pada penelitian ini, model yang ditawarkan untuk feedback yang diberikan pihak petugas terbagi menjadi 2 bagian. Tentunya ini akan membutuhkan skema bagan agar model dari proses tersebut dapat dimgerti. Diamana pada pembuatan sebuah sistem pengontrolan diperlukan sebuah gambar yang dapat menjelaskan alur ataupun langkah-langkah dari suatu sistem yang dibuat, sehingga dapat memberikan penjelasan dalam bentuk gambar. Penjelasan yang berupa proses merupakan gambar dari flowchart sistem yang akan dibuat. Tujuan dari pembuatan flowchart ini adalah untuk mempermudah pembaca dan pembuat sistem itu sendiri untuk dapat memahami langkah-langkah serta kemungkinan- kemungkinan dari beberapa keputusan. Desain menu utama sistem terdapat beberapa bagian untuk main menu, data pelanggar serta laporan. Pada bagian main menu terdapat dua menu yang dapat digunakan pihak petugas untuk menentukan jenis monitoring yang diigininkan. Jenis monitoring yang direncanakan adalah manual mode dan otomatis mode. Dimana dengan mode manual maka petugas sendiri yang akan melakukan proses monitoring dan melakukan respon terhadap pelanggaran oleh pemgendara. Selanjutnya pada bagian otomatis mode maka traffic monitoring tools akan bekerja secara otomatis untuk mendeteksi pelanggaran yang dilakukan oleh pengendara. Berikut adalah desain menu utama sistem traffic monitoing.
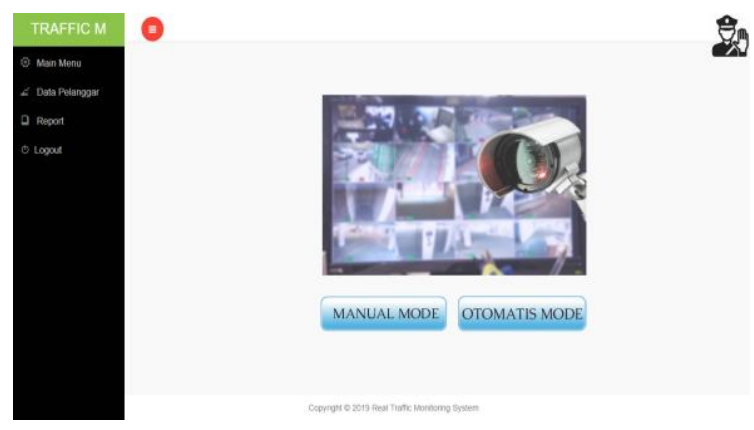

\section{Gambar 6. Desain Menu Utama Traffic Monitoring Sistem}

Sistem pengontrolan mode manual berjalan ketika ada petugas yang melakukan proses live monitoring. Pada gambar 7 dijelaskan bahwa sistem semula akan dalam keadaan standby. Petugas akan memantau aktifitas lalu lintas melalui monitor yang terdapat pada monitoring room. Petugas akan melakukan proses pelanggaran, apabila terdapat pelanggaran maka petugas akan memberikan respon. Respon yang diberikan petugas berupa peringatan atau teguran yang akan dilakukan dengan menggunakan microphone. Selanjutnya suara dari petugas akan ditransmisikan melalui cloud dan akan terdengar oleh pengendara pada perimpangan yang dituju dengan menggunakan speaker yang sebelumnya sudah di instalasi pada setiap persimpangan jalan. Selanjutanya petugas akan menuggu respon dari pelanggar, apabila pelanggar merespon peringatan dari petugas maka petugas akan melanjutkan proses monitoring lainnya. Jika pelanggar tidak merespon maka petugas akan mengulang kembali peringatan / teguran kepada pelanggar.

Adapun flowchart manual sistem monitoring lalu lintas dapat dilihat pada Gambar 7. 


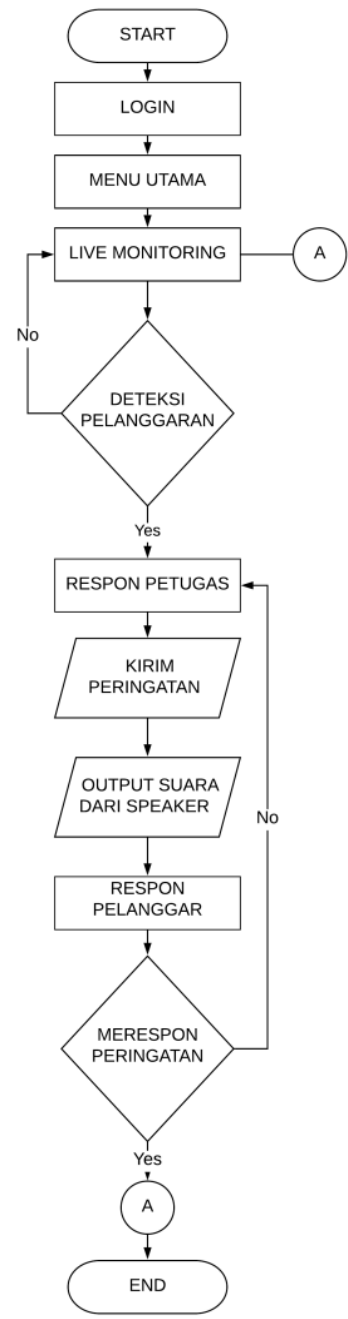

\section{Gambar 7. Flowchart Manual Real Monitoring Traffic System}

Pada gambar 8 dapat dijelaskan bahwa awal mula proses adalah petugas terlebih dahulu milih mode otomatis untuk mengatifkan sensor dan alat traffic monitoring akan bersiap dalam keadaan standby. Sistem terlebihg dahulu akan melihat kondisi lampu rambu lalu lintas, apabila sudah dalam keadaan rambu merah, maka sistem akan mengaktifkan sensor. Sensor akan ditempatkan dengan jarak sedemikian rupa sehingga dapat mendeteksi pelanggaran. Apabila ada pengendara yang melewati batas dari sensor maka sistem akan melakukan proses pengambilan foto dari pelanggar dan selanjutnya akan dikirim ke server untuk disimpan. Lalu sistem akan melakukan proses respon dengan menggunakan suara yang telah direkam terlebih dahulu untuk memperingatkan pelanggar. Agar sistem tidak mengalami kelebihan peringatan, maka sistem akan membatasi pengulangan automatisasi suara sebanyak tiga kali saja.

Adapun flowchart secara otomatis sistem monitoringlalu lintas dapat dilihat pada Gambar 8.

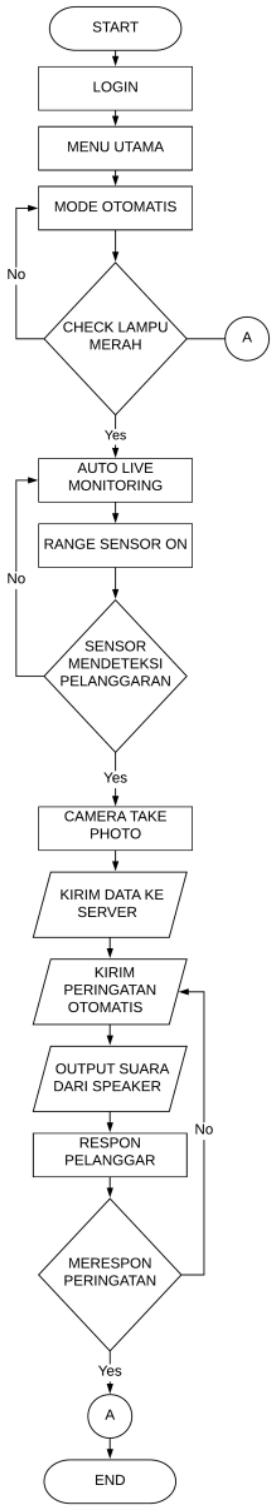

Gambar 8. Flowchart Automatic Real Monitoring Traffic System

\section{PENUTUP}

\section{Kesimpulan}

Pada penelitian ini berfokus pada rancangan, model dan model dari sistem real traffic monitoring. Model yang ditawarkan sangat bermanfaat bagi penerapan di kota-kota besar yang membutuhkan pengawasan extra terhadap pengendara di jalan raya. Model yang di tawarkan juga dapat terhubung dengan sistem E-Tilang dan E-Pajak sehingga dapat menambah keunggulan dari sistem yang akan dibangun nantinya. Dengan adanya penelitian mengenai model sistem real traffic monitoring ini, diharapkan dapat diimplementasikan kedalam bentuk karya cipta dan dapat berguna bagi masyarakat luas untuk mengurangi tingkat kecelakaan lalu lintas demi menciptakan suasana yang aman dan nyaman ketika berkendara. 


\section{Saran}

Hasil penelitian masih berupa model yang dibentuk untuk menjadi landasan penelitian lanjutan pada tahap implementasi alat serta sistem secara nyata. Sistem juga masih membutuhkan model instalasi jaringan agar dapat terintegrasi dengan baik. Diharapkan kedepannya penelitian ini dapat dikembangkan untuk mendukung model sistem Smart City.

\section{DAFTAR PUSTAKA}

[1] Gurning. Edy Halomonan. "Implementasi Undang-Undang Nomor 22 Tahun 2009 Tentang Lalu Lintas dan Angkatan Jalan Raya". https://www.bantuanhukum.or.id/

[2] Korlantas Porli. Grafik Fatalitas Kecelakangan di Indonesia. http://www.korlantas-irsms.info /graph/accidentData.

[3] N. Ying, W. Zhong-qin, R. Malekian, W. Ruchuan \& A. H. Abdullah. "Design of Accurate Vehicle Location System Using RFID”. Journal Elektronika Ir Elektrotechnika, VOL. 19, NO. 8, 2013. pp 105-110. 3

[4] Evizal, Rahman T.A \& Rahim S.K.A. RFID Vehicle Plate Number (E-plate) for Tracking and Management System. ICPADS 19th International Conference on Parallel And Distributed Systems. 2013. 4.

[5] Eun Kyu Lee, Young Min Yoo \& Chan Gook Park (2009). "Installation and Evaluation of RFID Readers on Moving Vehicle". VANET 09.5

[6] Wikipedia. 2018. Real user monitoring. https://en.wikipedia.org/wiki/Real_user_monit oring.

[7] F. Gushairon \& D.S. Joko. "Implementasi Voice Over Internet Protocol Menggunakan Raspberry Pi Dan Asterisk Untuk Pusat Panggilan Terintegrasi Pada Cv. Satuatap Camp". Sekolah Tinggi Manajemen Infor matika Dan Komputer Amikom Yogyakarta. 2016

[8] Wikipedia. 2018. "Android (Sistem Operasi)". https://id.wikipedia.org/wiki/Android_(sistem_ operasi).

[9] Wikipedia. Java.https://id.wikipedia.org/wiki/ Java.

[10] Andre. 2014. "Tutorial Belajar PHP Part 1: Pengertian Dan Fungsi PHP Dalam Pemograman Web". https://www.duniailkom. com/pengertian-dan-fungsi-php-dalampemograman-web/

[11] D. Pavithra \& B. Ranjith. "IoT based Monitoring and Control System for Home Automation". Proceedings of 2015 Global Conference on Communication Technologies (GCCT 2015)

[12] Hunt, V. Daniel, dkk. "RFID - A Guide to Radio Frequency Identification". New Jersey : Wiley Publishing, Inc.2007
[13] Lozano, Albert \& Nieto. "RFID Design Fundamentals and Applications". New York : CRC Press.2011. 